\title{
Pyrolysis of Anionic and Thermally Prepared Polystyrenes
}

\author{
Leo A. Wall,* Sidney Straus, Roland E. Florin \\ Institute for Materials Research, National Bureau of Standards, Washington, D.C. 20234 \\ and
}

Lewis J. Fetters

Department of Polymer Science, The University of Akron, Akron, Ohio 44325

(August 11, 1972)

\begin{abstract}
The changes in molecular weights, their distributions, and initial rates have been measured, for a series of polystyrenes prepared by thermal and anionic procedures. The information obtained and previous results can be explained to a very large extent by a kinetic chain decomposition comprised of competing end and random initiation, depropagation, intra- and intermolecular transfer and termination by combination.
\end{abstract}

Key words: Anionic polystyrene; molecular weight distributions; molecular weights; thermal polystyrene; polymers; polystyrene degradation; pyrolysis; thermolysis.

\section{Introduction}

For thermal polystyrenes the ratio of rate constants for random to end initiation has a value of $3 \times 10^{-4}$ initially. The present treatment assumes this value is constant with conversion. On the other hand the anionic polymers initiate at random in the limit of zero time, after which end-initiation begins to occur as the number of ends increases. The intermolecular transfer constant, zip length and kinetic chain length are dependent on the steady state radical concentration and are functions of the molecular weight. Their values, at the molecular weights present when the pyrolytic weight loss exceeds 5 percent, agree well with earlier estimates.

Some time ago a theory $[1,2]^{1}$ was developed for the thermal degradation of those polymers that undergo pure chain bond ruptures and hence in an open system are completely volatilized. The mechanism assumed was comprised of four elementary free radical processes: initiation, propagation, intermolecular transfer, and termination. The intent of the development was to provide a framework for the elucidation of the mechanisms of polymer degradation. For this and mathematical reasons the treatment assumed the initial polymer to be monodisperse. The change in molecular weight distribution [3, 4] observed during degradation of an initially monodisperse polymer

*Deceased.

${ }^{1}$ Figures in brackets indicate the literature references at the end of this paper. would be a quite sensitive indicator of the nature of the mechanism in many cases. Another limitation also for mathematical reasons was the restriction of the development to termination by disproportionation. At the time, long kinetic chain lengths were anticipated in many polymer decompositions $[5,6]$ and for such situations the method of bimolecular termination is of small consequence. Also, termination can be actually effectively first order if the degree of polymerization is shorter than the zip $[1,2]$ or kinetic chain length. A recent study of the decomposition of polytetrafluoroethylene [7] has, however, demonstrated that the mechanism for this polymer has a short zip length with termination mainly by combination. Evidence is accumulating that very short kinetic chain lengths are quite common.

One criticism of the earlier treatment $[1,2]$ that is not totally valid since some monodisperse polymers can now be prepared by appropriate polymerization techniques, has been that existing polymeric materials are polydisperse. Since the assumption that a "most probable" distribution exists in many polymers and is maintained throughout the degradation process simplifies the theoretical treatment, several efforts in this area were made $[8,9]$. It is also well known that random degradation in a closed system produces and maintains a most probable distribution and often only a small amount of a random component in the mechanisms can be the predominant factor in determining the distribution.

In our opinion, treatments in which the distribution is assumed for the initial and degrading polymers 
discard with that assumption much of their utility and value as a tool for the study of degradation mechanisms. These mechanisms are so varied and complex that every possible variable may be needed for the deduction of the details of the intermediate processes from experiments. For theoretical and experimental details on the problem of polymer degradation see more complete reviews $[10,11,12]$.

The work to be reported here is of importance for the questions raised in the above discussion and for the mechanism of polystyrene degradation. The degradation of polystyrene like the polymerization of styrene has been studied extensively and even from the most excellent of summaries [12] the situation appears confused. Until recently the shapes of the experimental thermal volatilization curves for polystyrene have not been produced by a fully a priori theory. However, with the use of computer evaluation the original theory $[1,2]$ was shown [13] to be able to nearly reproduce the experimental rate and molecular weight behavior. The results indicate that intermolecular transfer, end initiation, and zip lengths of the order of 5 are operative. Close comparison of theory with experiment did reveal certain imperfections, which do not invalidate the above conclusions but can be used to elucidate finer and more elusive details of the mechanism. An important discrepancy was the existence of somewhat higher values for the viscosity average degree of polymerization of the degraded polymer at conversions

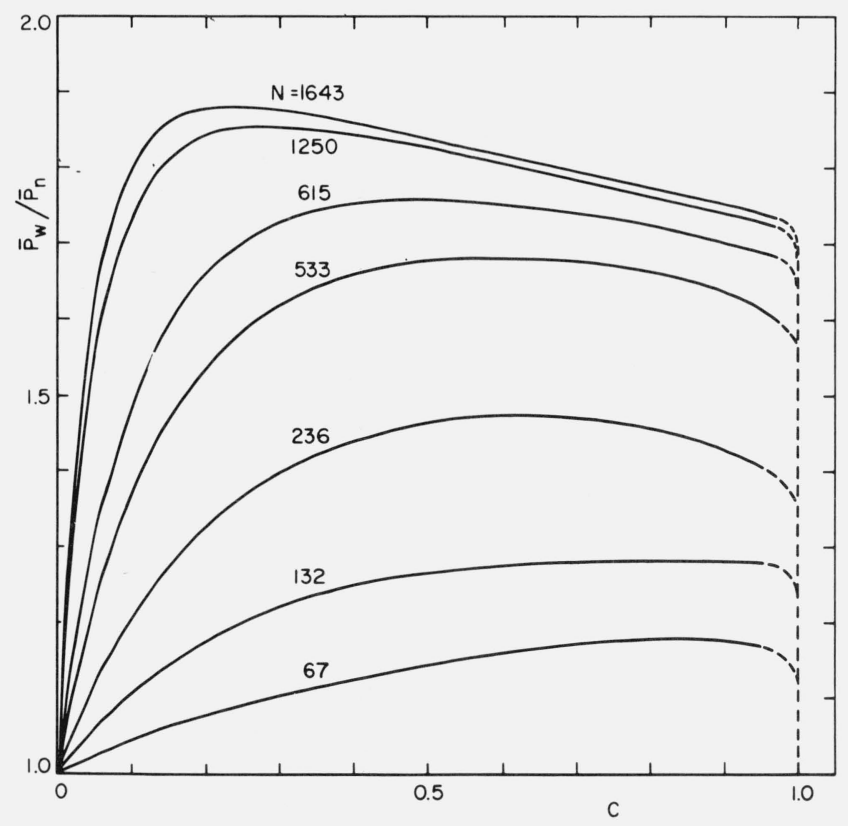

FIGURE 1. Theoretical variation of the ratio of weight to number average degrees of polymerization as a function of conversion and showing the influence of initial number average degree of polymerization, given on curves, for a mechanism consisting of end initiation transfer, depropagation [13] and termination by disproportionation. of 20 to 60 percent, than predicted from the level of the theoretical values for the weight average degree of polymerization. In the previous work [13] the distribution computed for the mechanism deduced from the then available experimental rate and molecular weight data was presented in terms of plots of the ratio of weight to number average degree of polymerization as a function of conversion (see fig. 1). It is seen that the initially monodisperse polymers rapidly approach the value of 2 initially and the higher their initial size the more rapidly the value increases. Since the polymers are volatilizing the ratio $\bar{P}_{w} / \bar{P}_{n}$ must return to one at complete conversion $(\mathrm{C} \rightarrow 1)$. The dashed sections of the curves were drawn to this limit intuitively. The full lines are computer calculated [13]. The surprising result is that with even the highest initial $\bar{P}_{n}$ of 1643 the "most probable" distribution is not achieved. Also the downward slope of the ratio above 20 percent conversion suggests that even if it started at the value of two it would decrease appreciably during the degradation probably to a value of 1.8. One reason the higher curves drop off is that the theory assumes that all species with a $\bar{P}_{n}$ lower than 9 evaporate instantly which narrows the distribution. Otherwise the curves depend on the competition between the intermolecular transfer, a randomizing process, and the volatilization of material.

A recent major study $[14,15,16]$ of the decomposition of polystyrene utilized poly ( $\alpha$-methylstyrene) [14] as catalyst for the polystyrene degradation, anionically prepared polystyrene with specifically formed thermolabile structures [15] and carbon 14 labeled polystyrene [16]. The results of this very extensive experimentation raise many points but the most interesting aspects are: (1) the confirmation of short zip lengths of approximately 3 , (2) 1.2 intermolecular transfer steps per radical formed, (3) strong evidence for termination by combination with the possibility that the cage effect may tend to make termination kinetically first order. In this article we shall present evidence which is in the main compatible with the above items. Short zip lengths and intermolecular transfer are in our opinion now well established in polystyrene.

\section{Experimental Data}

In this work a series of monodisperse polystyrenes with number average molecular weights in the range of 1,000 to 200,000 were prepared anionically [17] and studied. The two National Bureau of Standards Standard Reference Polymers 705 and 706 were also studied in more detail than previously [13].

Rate of volatilization experiments were carried out using $10 \mathrm{mg}$ sample in high vacuum and a recording electrobalance.

For molecular weight measurements, approximately $400 \mathrm{mg}$ samples were pyrolyzed in a high vacuum apparatus to the desired extents of conversion and the molecular weights of the residue determined by both light scattering and membrane osmometry. 


\section{Polymer Characterization}

The molecular weight averages were determined on commercial instruments. Number-average molecular weights were determined on Hewlett-Packard 501 and 502 osmometers. ${ }^{2}$ Low-molecular weight material was characterized on the Hewlett-Packard vapor pressure osmometer 301. The light scattering was done on the Bausch and Lomb PGD instrument. The number-average molecular weights were determined in toluene at $37{ }^{\circ} \mathrm{C}$ with gel cellophane 600 membranes. From the linear plot of $\pi / \mathrm{c}$ versus concentration, the molecular weights were derived. Previous experience with near monodisperse polystyrene had shown that number average molecular weights as low as $5 \times 10^{3}$ could be determined on these high-speed membrane osmometers with no diffusion of solute through the membrane. The permeation limit of the membranes was checked in the following fashion. A series of low-molecular weight polystyrenes were synthesized by anionic polymerization [18] and were characterized on the vapor pressure osmometer. They were then recharacterized on the high speed membrane osmometer. The predicted osmotic pressures were obtained at all concentrations. The conclusion was drawn that the membranes used in this work had permeation limits of $5 \times 10^{3}$ or less. Similar conclusions have been reached elsewhere [19]. Thus, the number-average molecular

${ }^{2}$ Certain commercial equipment, instruments, or materials are identified in this paper in order to adequately specify the experimental procedure. In no case does such identification imply recommendation or endorsement by the National Bureau of Standards, nor does it imply that the material or equipment identified is necessarily the best available for the purpose. weights reported herein are believed not to be vitiated by permeation of low molecular weight solute through the membrane.

The weight-average molecular weights were determined at $25 \pm 0.5{ }^{\circ} \mathrm{C}$ in benzene. Solutions were filtered twice prior to use through solvent resistant filters. Millipore or Selas Flotronics membranes of $0.45 \mu \mathrm{m}$ pore diameter were used. Measurements were made on four different concentrations between the angles of 30 and $150^{\circ}$. Unpolarized light of $546 \mathrm{~nm}$ was used with the value of $15.8 \times 10^{-6} \mathrm{~cm}^{-1}$ being adopted for Rayleigh's ratio. The value of $d n / d c$ was $0.106 \mathrm{ml} \mathrm{g}^{-1}[20,21]$. The $d n / d c$ values for several partially degraded polystyrenes were checked, at $25 \pm 0.01{ }^{\circ} \mathrm{C}$, in a commercial differential refractometer, Phoenix Precision Instrument Company. These $d n / d c$ values were identical to the published values $[20,21]$.

The weight-average molecular weights of some of the undegraded samples were determined by gel permeation chromatography measurements. For molecular weights up to $10^{3}$ a set of five columns in the commercial instrument, The Waters Ana-Prep GPC, were used. These columns had permeability ranges of $50-80,80-100,100-350,350-700$, and $700-2000 \AA$ (angstroms). The five columns used for the higher molecular weight samples were those with permeability ranges of $2-5 \times 10^{3} \AA$, two columns with $5-15 \times 10^{3} \AA, 1.5-5 \times 10^{4} \AA$ and $5-15 \times 10 \AA$. These columns were calibrated with characterized polystyrene samples of both narrow and broad molecular weight distributions. The solvent used was tetrahydrofuran at a temperature of $30^{\circ} \mathrm{C}$.

The polystyrenes used in this study are listed in table 1. The first column gives for the anionically

TABLE 1. Polystyrenes used in this investigation

\begin{tabular}{|c|c|c|c|c|c|}
\hline \multicolumn{4}{|c|}{ Number average molecular weight, $\bar{M}_{n}$} & \multirow{2}{*}{$\bar{M}_{v}[22]$} & \multirow{2}{*}{$\bar{M}_{w}(\mathrm{GPC})$} \\
\hline Chemical & $\begin{array}{c}\text { Vapor pressure } \\
\text { osmometry }\end{array}$ & $\begin{array}{l}\text { Membrane } \\
\text { osmometry }\end{array}$ & $\begin{array}{l}\text { Values used } \\
\text { in plots }\end{array}$ & & \\
\hline $\begin{array}{l}\text { Anionic } \\
1,150 \\
2,250 \\
3,900 \\
5,300 \\
10,300 \\
16,800 \\
20,800 \\
43,000 \\
54,000 \\
(\text { NBS } 705) \\
\\
\text { Thermal } \\
\left(180^{\circ} \mathrm{C}\right) \\
(\mathrm{NBS} 706) \\
\left(120^{\circ} \mathrm{C}\right) \\
\left(60^{\circ} \mathrm{C}\right)\end{array}$ & $\begin{array}{r}1,100 \\
2,450 \\
3,700 \\
5,300 \\
11,400\end{array}$ & $\begin{array}{r}12,000 \\
22,000 \\
25,000 \\
37,000 \\
49,000 \\
73,000 \\
170,900 \\
\\
90,000 \\
130,000 \\
152,000 \\
254,000\end{array}$ & $\begin{array}{r}1,100 \\
2,450 \\
3,700 \\
5,300 \\
11,400 \\
20,000 \\
22,500 \\
37,000 \\
48,500 \\
73,000 \\
170,900 \\
\\
\\
90,000 \\
130,000 \\
152,000 \\
254,000\end{array}$ & $\begin{array}{r}8,500 \\
12,500 \\
20,000 \\
22,500 \\
38,000 \\
48,500 \\
75,000 \\
180,000\end{array}$ & $\begin{array}{c}7,200 \\
12,000 \\
22,000 \\
25,000 \\
(38,000 \text { L.S. }) \\
50,000 \\
75,000 \\
(179,000 \text { L.S }) \\
\\
115,000 \\
(272,000 \text { L.S. }) \\
230,000 \\
330,000\end{array}$ \\
\hline
\end{tabular}

(L.S. = Light Scattering) 
prepared samples the number-average molecular weight estimated from the ratio of catalyst to monomer used. The number in parenthesis gives the temperature of polymerization for the thermally prepared polymer or identifies one of the two standard samples issued by the National Bureau of Standards. The fourth column lists the number-average molecular weight values used for plotting and calculations described here.

The experimental values for $M_{n}$ (vapor pressure) and $M_{w}(\mathrm{GPC})$ are estimated to be within \pm 5 percent of the true value and for $M_{n}$ (membrane) within \pm 7 percent. The viscosity averages, $M_{v}$, were calculated from the relation [22].

$$
[\eta] \underset{\text { benzene }}{30}{ }^{\circ} \mathrm{C}=8.5 \times 10^{5} M_{v}{ }^{0.75}
$$

This relation is not accurate for very low molecula weights. Thus, the two lowest $M_{v}$-values and in particular the 8,500 values are excessively high.

\section{Results}

\subsection{Molecular Weight Change With Pyrolysis}

In figure 2 we show the experimental variation of both the weight average, $\bar{P}_{w}$, and number average, $\bar{P}_{n}$, degrees of polymerization for two initially monodispersed polystyrenes. The upper curves are for the sample having an initial number-average molecular

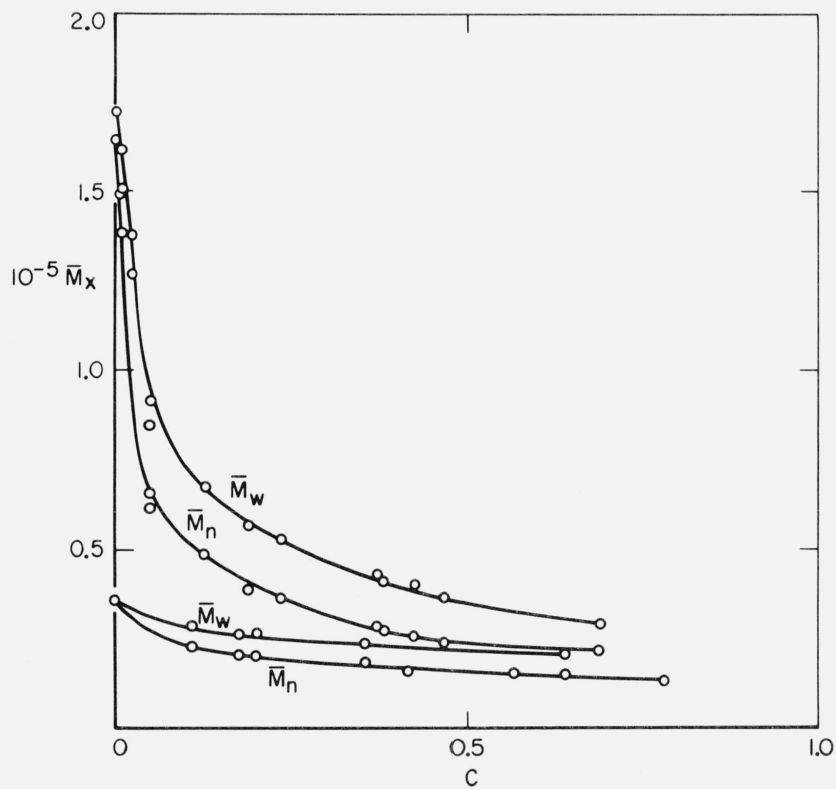

FIGURE 2. Variation of the weight and number average molecularweights of polystyrene during thermal degradation at $300^{\circ} \mathrm{C}$.

Upper curves, NBS Sample 705, monodisperse anionic polystyrene, initial $\bar{M}_{n}=170,900$, initial $\bar{M}_{v d} d \bar{M}_{n}=1.06$

Lower curves monodisperse anionic polystyrene initial $\bar{M}_{n}=37,000$. Initial $\bar{M}_{w 0} / \bar{M}_{n}=$ 1.03 . weight of 170,900 . The lower curves are for the polymer having an initial number-average molecular weight of 37,000 . The sharp initial drop of the $\bar{P}_{n}$ and $\bar{P}_{w}$ for the polymer with the higher initial values indicate a random rupture process which we attribute to intermolecular transfer. It is evident that the $\bar{P}_{w} / \bar{P}_{n}$ ratio does not become two even at conversion of 70 percent. As might be expected this ratio increases with conversion much less for smaller polymer than for the larger. Qualitatively their behavior or the pattern of the results is in the direction anticipated from figure 1 except that the $\bar{P}_{w} / \bar{P}_{n}$ ratios are appreciably smaller. In figure 3 there is similar data for an initial polydisperse thermally polymerized polystyrene with an initial $\bar{P}_{w} / \bar{P}_{n}$ ratio of 2.1 . It is evident from this figure that the ratio is decreasing and the distribution is narrowing as the degradation proceeds. Table 2 presents the basic data used for figures 2 and 3 .

In figure 4 we present a plot of the variation in the $\bar{P}_{w} / \bar{P}_{n}$ ratio for these three polymers as a function of conversion that is volatilization. It seems clear from this plot that provided the initial molecular weight is sufficiently large the ratio tends to the value of 1.5 very quickly as degradation proceeds. From the theoretical curves in figure 1 we expect a slow narrowing of the distribution if the samples were initially polydisperse. Samples of the polydisperse polymer that were pyrolyzed to about 0.5 conversion values were also studied with gel permeation chromatography (GPC). They were found to have smooth monomodal

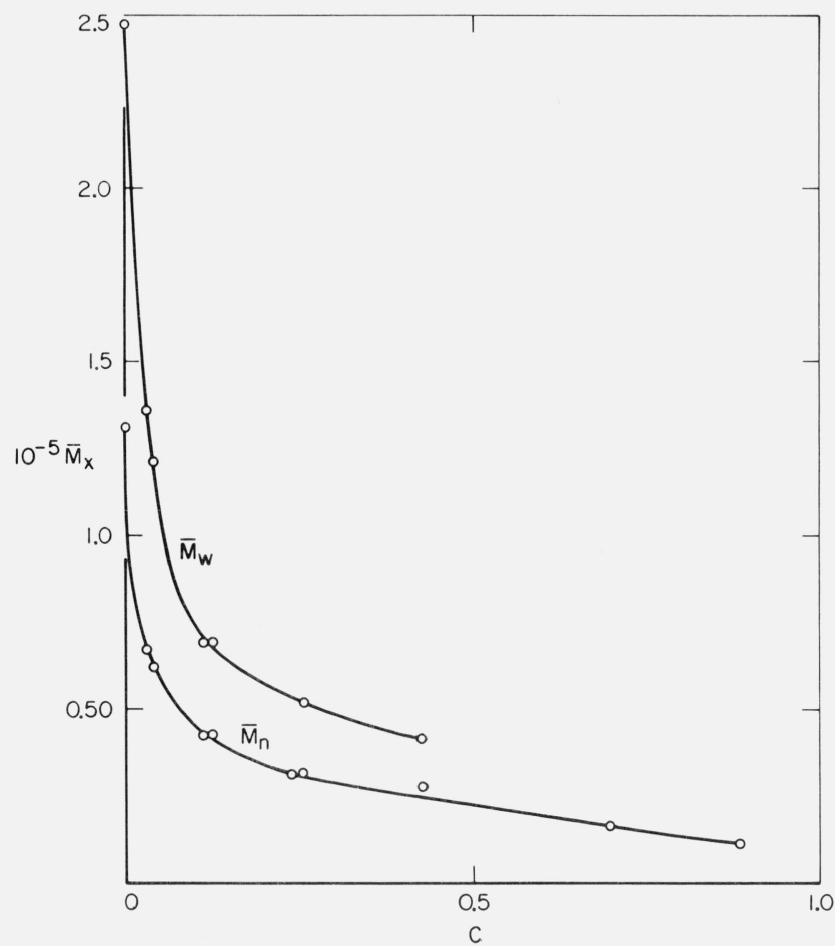

FIGURE 3. Variation of the weight and numva, average molecular weight of polystyrene during thermal degradation at $300^{\circ} \mathrm{C}$.

NBS Sample 706. Initial $\bar{M}_{n}=130,000$, initial $\bar{M}_{w d} / \bar{M}_{n}=2.1$ 
TABLE 2. Thermal degradation of polystyrenes, number average, $\mathrm{M}_{\mathrm{n}}$ and weight average, $\overline{\mathrm{M}}_{\mathrm{w}}$ molecular weights after a given loss of weight for the sample

\begin{tabular}{|c|c|c|c|}
\hline Polymer & Weight loss \% & $10^{-4} \bar{M}_{n}$ & $10^{-4} \bar{M}_{w}$ \\
\hline $\begin{array}{l}\text { Monodisperse } \\
\qquad \bar{M}_{n}(0)=3.7 \times 10^{+4}\end{array}$ & $\begin{array}{l}10.9 \\
17.6 \\
20.1 \\
35.6 \\
41.8 \\
56.9 \\
64.1 \\
78.2\end{array}$ & $\begin{array}{l}2.4 \\
2.1 \\
2.1 \\
1.9 \\
1.7 \\
1.7 \\
1.6 \\
1.4\end{array}$ & $\begin{array}{c}3.0 \\
2.7 \\
2.8 \\
2.5 \\
\ldots \ldots \ldots \\
\ldots \ldots . . \\
2.2 \\
\ldots \ldots \ldots\end{array}$ \\
\hline $\begin{array}{l}\text { Monodisperse } \\
\qquad \bar{M}_{n}(0)-17.09 \times 10^{+4} \\
\text { NBS } 705\end{array}$ & $\begin{array}{c}0.65 \\
0.93 \\
2.3 \\
4.9 \\
5.0 \\
12.8 \\
18.9 \\
23.5 \\
37.4 \\
38.3 \\
42.6 \\
47.0 \\
69.0\end{array}$ & $\begin{array}{r}15.4 \\
14.4 \\
13.2 \\
6.4 \\
6.9 \\
5.1 \\
4.0 \\
3.8 \\
3.0 \\
2.9 \\
2.8 \\
2.5 \\
2.3\end{array}$ & $\begin{array}{r}16.8 \\
15.6 \\
14.3 \\
8.8 \\
9.5 \\
7.0 \\
5.9 \\
5.5 \\
4.5 \\
4.3 \\
4.2 \\
3.8 \\
3.1\end{array}$ \\
\hline $\begin{array}{l}\text { Polydisperse } \\
\bar{M}_{n}(0)=13.0 \times 10^{+4} \\
\text { NBS } 706\end{array}$ & $\begin{array}{r}3.1 \\
4.0 \\
11.2 \\
12.5 \\
23.8 \\
25.6 \\
42.7 \\
69.8 \\
88.8\end{array}$ & $\begin{array}{l}7.0 \\
6.5 \\
4.4 \\
4.4 \\
3.2 \\
3.3 \\
2.9 \\
1.7 \\
1.2\end{array}$ & $\begin{array}{c}14.1 \\
12.6 \\
7.2 \\
7.2 \\
\ldots \ldots \ldots \\
5.4 \\
4.4 \\
\ldots \ldots \ldots\end{array}$ \\
\hline
\end{tabular}

distributions with $\bar{P}_{w} / \bar{P}_{n}$ ratio of 1.7 . However, it has been found $[23,24]$ that these ratios when obtained from GPC are in general larger than when obtained from light scattering and osmometry by about 10 percent [23] which would bring our GPC result into good agreement with the values shown in figure 4 . A $1.5 P_{w} / P_{n}$ ratio has also been reported [25] for monodisperse polystyrene that has been mechanically degraded in the absence of oxygen.

Molecular weight measurements were carried out on other pyrolyzed monodisperse polymers listed in table 1. For theoretical reasons our particular interest was to ascertain the behavior of low molecular weight materials (see fig. 5). The results are similar to those obtained in an earlier study [13] on fractions of thermally polymerized polymers, in that with low initial $\bar{M}_{n}$ values the molecular weight remains nearly constant through conversions greater than 50 percent. For example, the $5,300 \bar{M}_{n}$ sample shows about a 15 percent decrease in $\bar{M}_{n}$ at 70 percent conversion. From earlier work [13] on fractions of thermally prepared polymer, the data on a $7,000 \bar{M}_{n}$ sample

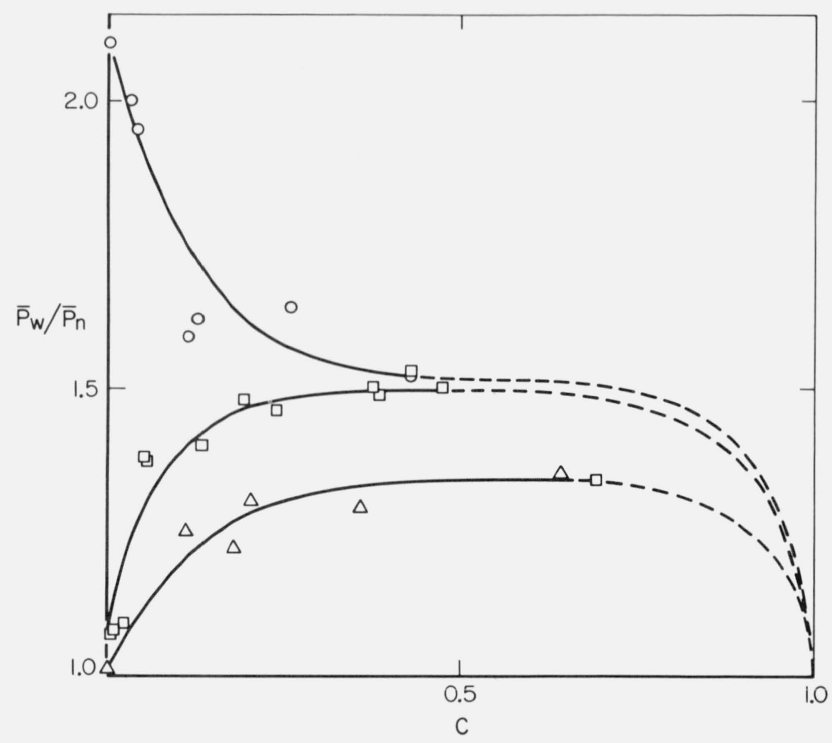

FIGURE 4. Variation of the ratio of weight to number average degrees of polymerization of polystyrene during thermal degradation at $300^{\circ} \mathrm{C}$.

, NBS Sample 706, polydisperse

Initial $\bar{P}_{n}=1.26 \times 10^{3}$

NBS Sample 705, monodisperse

Initial $\overline{\boldsymbol{P}}_{n}=1.64 \times 10^{3}$

$\triangle$, Polystyrene, monodisperse

Initial $\bar{P}_{n}=3.58 \times 10^{2}$.

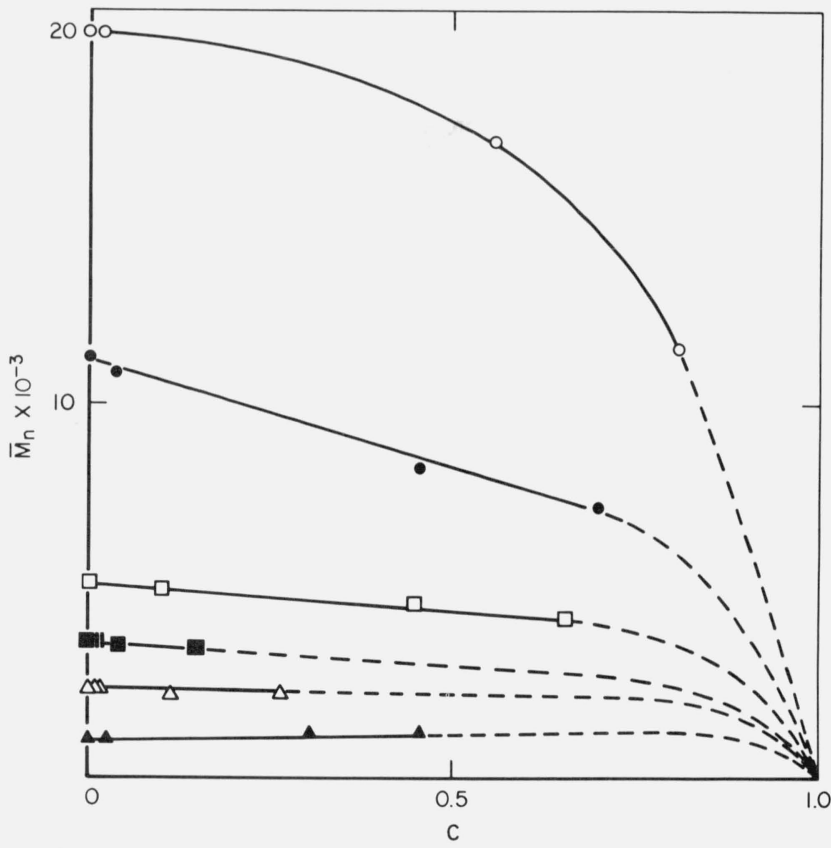

FigURE 5. Thermolysis of monodisperse polystyrenes at $300{ }^{\circ} \mathrm{C}$.

Variation of Number Average Molecular Weight (vapor pressure osmometry) with conversion.

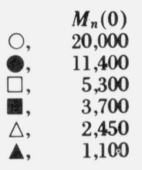


was extrapolated to show a 29 percent molecular weight decrease at 70 percent conversion. For the two types of polymers, nearly identical behavior is therefore exhibited in their molecular weight dependence on conversion at low initial molecular weights. It is noted that at 70 percent conversion the molecular weights of the two polymers are essentially the same.

\subsection{Rate of Volatilization}

An extensive comparison of the rate of volatilization of the monodispersed polystyrene with those of thermal polymers and their fractions [13] was made. With high molecular weight polymers the rates were essentially independent of the type of polymer, anionic or thermal. In previous work [13] it had been seen that beginning at $\approx 25,000 \bar{M}_{n}$ the typical maximum in the rate at $\approx 40$ percent conversion was eliminated. With the anionic polymers studied here a maximum in the rate versus conversion curves persists down to $5,300 \bar{M}_{n}$ and below. In figure 6 we show rate for $48,000 \bar{M}_{n}$ and $5,300 \bar{M}_{n}$ anionic polymers. The curve for the 48,000

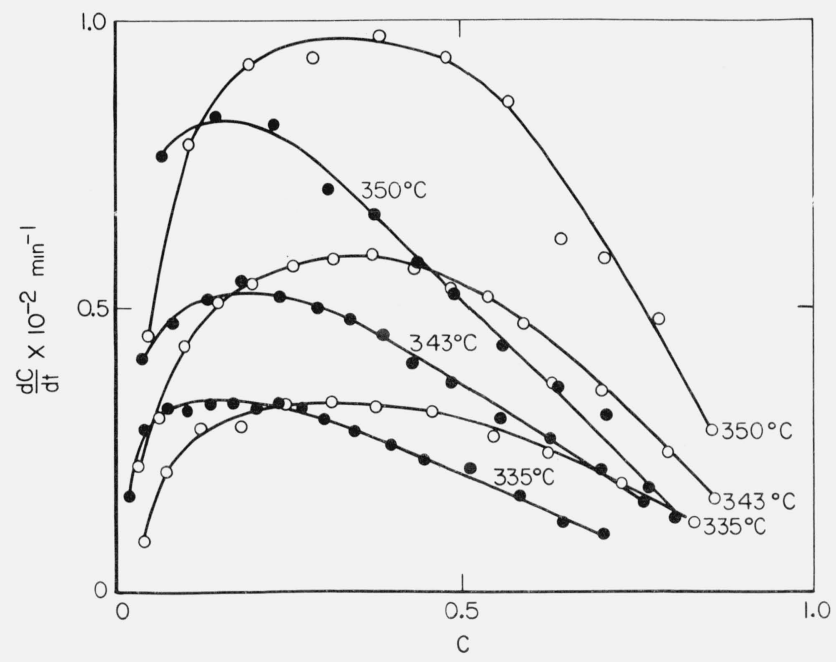

FIGURE 6. Thermolysis of monodisperse polystyrenes, variation of the rate of volatilization with conversion.

$M_{n}(0)$ Activation energy, $\mathrm{kcal} / \mathrm{mol}$, based on maximum rate.

$$
\begin{array}{ll}
0,48,500 & 51 \\
5,300 & 45
\end{array}
$$

$\bar{M}_{n}$ polymer is nearly typical of all polystyrenes of higher molecular weights. However, with the anionic polymers of less than $48,000 \bar{M}_{n}$, the maxima shift to lower conversion and the curves exhibit behavior theoretically predicted for simple random scission. At such low $\vec{M}_{n}$ values thermal polymer has high initial rates decreasing with conversion [13].

\subsection{Initial Rates}

In a typical isothermal volatilization measurement the behavior below 5 percent conversion is usually ignored Heat-up time for the sample and the loss of volatile impurities interfere with the determination of the initial rates, which are therefore not typical of the polymer at a known temperature. On the other hand, the decomposition is believed to be initiated at the chain ends and hence the initial rates of volatilization should show a dependence on the number of chain ends or equivalently the reciprocal number average molecular weight.

In this work we very carefully looked at the rates in the range of $0-5$ percent conversion. This entailed making runs at lower temperatures of 287, 300, and $310^{\circ} \mathrm{C}$. For the monodisperse and anionically prepared polymers the initial rates as a function of conversion are shown in figure 7 . It is seen that no straight line extrapolation to zero conversion is possible since the rates rise with continually decreasing slopes in the

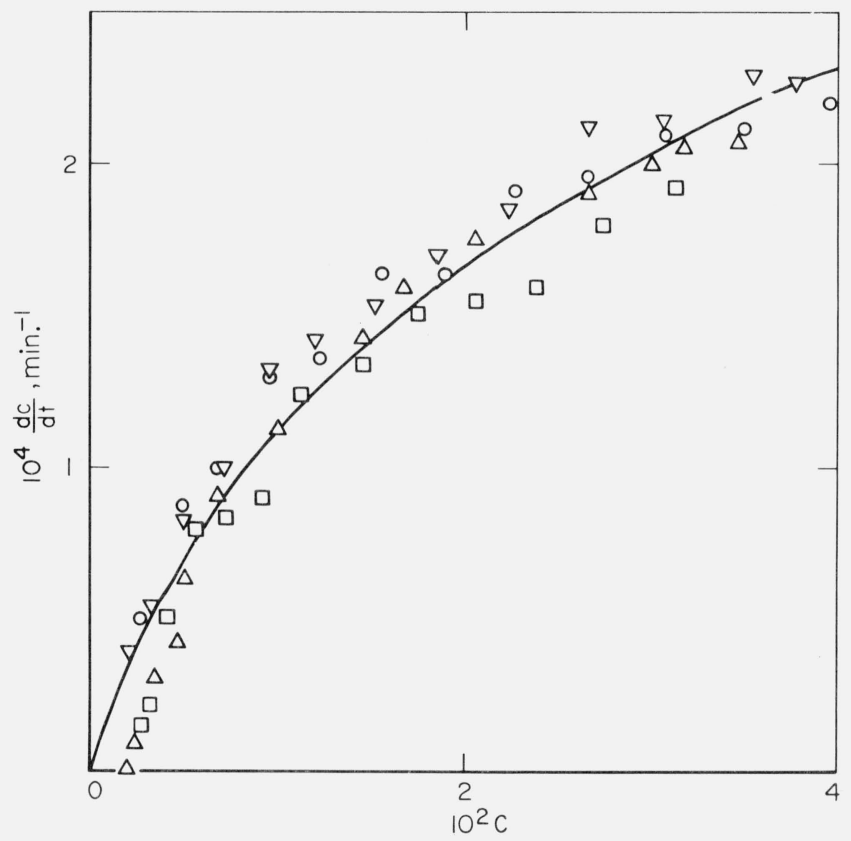

FIGURE 7. Thermolysis of anionic polystyrenes at $300^{\circ} \mathrm{C}$, variation of rate in the low conversion range, effect of number average molecular weight.

$$
\begin{gathered}
M_{n}(0) \\
\nabla, \quad 22,500 \\
\bigcirc, \quad 48,500 \\
\triangle, \quad 170,000 \\
\square, 230,000
\end{gathered}
$$

manner shown. The rates at zero conversion are evidently zero and independent of the molecular weight of sample. As the process of decomposition proceeds an effect of molecular weight develops such that the lower molecular weight polymers have higher rates.

For thermally prepared polystyrenes the rates at these low conversions are essentially independent of conversion and are easily extrapolated back to zero conversion as shown in figure 8 . The initial rates are strongly dependent on the reciprocal of the molecular weights of the samples. A plot of the log of these initial rates as a function of the logarithm of the reciprocal number average molecular weights of the sample gave straight line relations with slopes of $0.24,0.27$, and 0.28 for measurements at the respective temperatures, 310,300 , and $287^{\circ} \mathrm{C}$. 


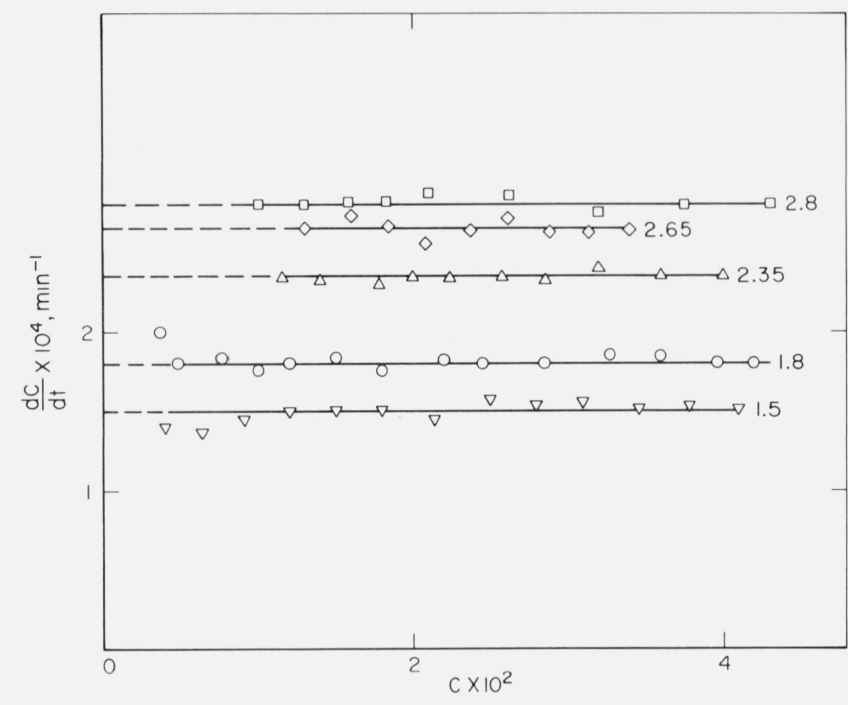

FigURE 8. Thermolysis of thermal polystyrenes at $300^{\circ} \mathrm{C}$, variation of rate in the low conversion range, effect of number average molecular weight.

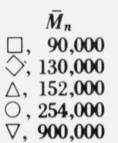

\section{Discussion}

\subsection{Theory}

The mechanism of decomposition of carbon chain polymers has been most successfully interpreted in terms of free radical mechanisms $[10,11,12]$. However, it can be said that complete elucidation of a given polymer has only been approached in the case of polytetrafluoroethene $[7,26]$. Exact quantitative treatment of polymer decomposition mechanisms is difficult due to the complexity of the mechanisms in the condensed phase in which they occur and the large effort required for obtaining an adequate number of reliable measurements. Our objective here is to obtain the best quantitative fit to the observed measurements based on the assumption of a mechanism with a minimum number of elementary steps. We may and will neglect processes known to occur, depending on their importance relative to key assumptions. Although in previous work $[13,27]$ computers were utilized for quantitative treatment of thermal decomposition mechanisms, we have in this work considered numerous possible special cases. The advantage in general is that with the steady state assumption many cases are amenable mathematically, giving the desired relations in closed form.

The mechanisms considered initially in our effort to treat the mechanism of thermal decomposition of polystyrene encompass all of the following possible elementary reactions, which are symbolically depicted. The number of polymer molecules with $i$ units in the chain is represented as $Q_{i}$ and the number of radicals with $i$ units as $R_{i}$. Monomer is represented by $M$ although $Q_{i}$ could be an alternative representation. Bimolecular rate terms have the volume of the polymer, $V$, in the denominator since $R_{i}$ and $Q_{i}$ are numbers not concentrations.

\section{Initiations}

random

end

specific interior

Propagation

Transfer

intramolecular

intermolecular

$$
Q_{i} \longrightarrow R_{i-j}+R_{j}
$$

$Q_{i} \stackrel{e<<L}{\longrightarrow} R_{i-e}+R_{e} \uparrow$

$$
Q_{i+j} \longrightarrow R_{i}+R_{j}
$$

$R_{i} \longrightarrow R_{i-1}+M \uparrow$

$$
R_{i} \longrightarrow Q_{i-j} \uparrow+R_{j}
$$$$
k_{3}^{\prime} \sum_{L}^{\infty} R_{i}
$$$$
k_{l r} \sum_{L}^{\infty}(i-3) Q_{i}
$$$$
2 k_{l e} \sum_{L}^{\infty} Q_{i}
$$$$
k_{l s} \sum_{L}^{\infty} Q_{i+j}
$$$$
k_{2} \sum_{L}^{\infty} R_{i}
$$

$$
R_{i}+Q_{j} \longrightarrow Q_{i}+R_{j}^{\prime} \quad \frac{k_{3} \sum_{L}^{\infty} R_{i} \sum_{L}^{\infty} j Q_{j}}{V}
$$

$$
R_{j}^{\prime} \stackrel{>>k_{3}}{\longrightarrow} Q_{j-k}+R_{k}
$$




$$
R_{i}+R_{j} \longrightarrow Q_{i}+Q_{j}
$$

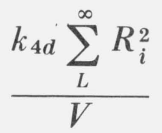

combination

$$
R_{i}+R_{j} \longrightarrow Q_{i+j}
$$

$$
\frac{k_{4 c} \sum_{L}^{\infty} R_{i}^{2}}{V}
$$

cage disproportionation

$$
\left[R_{i}+R_{j}\right] \longrightarrow Q_{i}+Q_{j}
$$

$$
k_{[4 d]} \sum_{L}^{\infty} R_{i}
$$$$
k_{[4 c]} \sum_{L}^{\infty} R_{i}
$$

cage combination

$$
\left[R_{i}+R_{j}\right] \longrightarrow Q_{i+j}
$$

$$
R_{L} \stackrel{i<L}{\longrightarrow} R_{i} \uparrow+M \uparrow
$$

$k_{2} R_{L}$

evaporative ( $p$-type)

evaporative ( $t$-type)

$$
R_{i} \stackrel{j<L}{\longrightarrow} Q_{i-j}+R_{j} \uparrow
$$

where $\phi$ is a fractional efficiency factor arising from the fact that the radical precursor may decompose in several ways and the vertical arrows indicate key possibilities for volatile production.

With transient free radical mechanisms the minimum number of steps comprising a mechanism would include one initiation and one termination process. Since we list three initiation and six termination processes this means eighteen possible mechanisms. Inclusion of one of the propagation or transfer steps produces 54 additional mechanisms for a total of 72. Any combination of the processes is possible so that the total number of mechanisms is very large. On the other hand the kinetic behaviors possible are much fewer since the kinetic form of many of the initiation and termination steps is similar.

Since there are twelve processes listed above any complete mathematical treatment would lead to such complex and intractable equations and such a large number of parameters that even with the assistance of computers an understanding of the model and an elucidation of a mechanism would be a long and tedious task.

We choose therefore to explore the possibilities with somewhat intuitive simplifications. Our primary measurement is the weight loss of the polymer. Hence the conversion, $C$ is defined as:

$$
C=1 \frac{W(t)}{W(0)}
$$

where $w(0)$ is the initial weight of sample and $w(t)$ the weight at time, $t$. The rate of conversion is then:

$\frac{d C}{d t}=\frac{m}{W(0)} \frac{d^{\prime \prime} M "}{d t}=\frac{m}{w(0)}\left[k_{2} \sum_{L}^{\infty} R_{i}(t)+\frac{d \sum_{2}^{L-1} i Q_{i}(t)}{d t}\right]$ where " $M$ " symbolizes total volatiles in terms of monomer segments, $m$ is the molecular weight of monomer, and $L$ is the smallest degree of polymerization that must chemically decompose in order to vaporize. For polystyrene the $k_{2}$ term represents at least 42 percent of the process since the monomer yield is about 42 percent and is nearly independent of conversion in the 0 to 75 percent conversion range. The second term on the right represents the production of nonmonomer, which can arise in a variety of ways depending on the assumed mechanism. It should be noted that intramolecular transfer may be expected to produce volatiles and if so would have the same kinetic form as propagation. Since the number average molecular weight is also experimentally available, the variation with time of the number of polymer molecules is an important aspect of the problem. With the use of a steady state approximation for the number of radicals one obtains:

$$
\begin{aligned}
& \frac{d Q(t)}{d t}=\frac{k_{3} R(t)\left[P_{n}(t)-1\right] Q(t)}{V(t)}+\frac{k_{4 d} R(t)^{2}}{V(t)} \\
&+k_{[4 d]} R(t)+1 / 2 \phi k_{3}^{\prime} R(t)-k_{\iota s} O(t)-1 / 2 k_{2} R_{L}(t) \\
&-\sum_{1}^{L-1} f_{i} Q_{i}(t) .
\end{aligned}
$$

Here $Q(t)$ represents $\sum Q_{i}(t)$ the sum of all the molecules in the reacting system, $R(t)$ is the same for all radicals and $V(t)$ is the volume of the system from which volatiles are escaping.

These quantities are functions of time since $Q$ and $R$ are in units of moles, not concentrations. From eq 
(3) it is seen that $Q(t)$ is increased by intermolecular transfer and disproportionation steps and decreased by end initiation and evaporative processes. The factors $f_{i}$ are the probabilities of evaporation of the particular species. In this discussion these evaporative processes will be ignored on the assumption that their effect is small since throughout the conversion range of 0 to 80 or 90 percent the molecular weight of the polymer remains quite large. The molecular weight changes and rates of volatilization as functions of conversion are similar for both monodisperse (anionic) and polydisperse (thermal) polystyrenes of high molecular weight. Thus no distinct indications of a fundamental difference in mechanism of decomposition of these type of polymers has been obtained previously. However the rate behaviors at low conversions, shown in figures 7 and 8, clearly point out a strong difference in their initiation processes. Therefore we shall discuss the two types of polymers separately.

\subsection{Thermal Polystyrenes}

If volatiles had been produced by the $k_{1 e}$ process then the initial rates should depend on the first power of the reciprocal molecular weight. Production of volatiles by the $k_{2}$ step and bimolecular termination would give with end initiation a 0.5 power dependence and with random initiation a zero power dependence. The observed dependence, figure 8 , for the thermal polymers, at three different temperatures was from 0.24 to 0.28 . This result, plus the character of the initial rates for the anionic polymer, figure 7 , and the presence of a maximum in the rate curve for the 5,300 $M_{w}$ anionic polymer, figure 6 , strongly suggests that random initiation is occurring in competition with end initiation.

The molecular weight distribution data, figure 4, indicates termination by combination. Other coupling processes such as alkylation of the phenyl group via radical addition reactions could explain the narrowing of the molecular weight distribution. However, the solution viscosity of pyrolyzed polymers does not indicate the branching one might then expect. As will be seen below our results are incompatible with suggestions $[12,16]$ that termination is first order.

Transfer and propagation are evident from earlier work $[13,16]$. We therefore use these five elementary steps for evaluating the result on the thermal polystyrenes. Although our treatment gives each molecule a particular probability for random and end initiation, the actual mechanism probably involves a specific number of end initiating sites on particular molecules.

\subsection{Raie of Volatilization}

All weight loss is assumed to arise from the depropagation of large radicals

$$
\frac{d C}{d t}=\frac{m}{W(0)} \frac{d M}{d t}=\frac{m}{W(0)} k_{2} R
$$

The steady state number of radicals is obtained from

$$
\begin{gathered}
2 k_{4 c} \frac{R^{2}(t)}{V(t)}=2 k_{1 r} \bar{P}_{n}(t) Q(t)+2 k_{1 e} Q(t) \\
R(t)=\left[\left(1+\gamma \bar{P}_{n}(t)\right)\left(\frac{k_{1 e}}{k_{4 c}} \frac{\rho}{m} \frac{1}{\bar{P}_{n}(t)}\right)\right]^{1 / 2} V(t)
\end{gathered}
$$

where $\gamma=k_{1 r} / k_{1 \prime e}, \bar{P}_{n}$ the number average degree of polymerization and $\rho$ the density of the polymer. From eqs (4) and (6) it follows that:

$$
\begin{gathered}
\frac{d C}{d t}=k_{2}\left(\frac{k_{1 e} m}{k_{4 c} \rho}\right)^{1 / 2}\left(\gamma+\frac{1}{\bar{P}_{n}(t)}\right)^{1 / 2} \quad(1-C) \\
=\frac{k_{1 e}}{\beta}\left(\gamma+\bar{P}_{n}(t)^{-1}\right)^{1 / 2} \quad(1-C)
\end{gathered}
$$

and at $C=0$

$$
\begin{aligned}
\left(\frac{d C}{d t}\right)_{0}^{2}=k_{2}^{2}\left(\frac{k_{1 e}}{k_{4 c}} \frac{m}{\rho}\right)(\gamma & \left.+\frac{1}{\bar{P}_{n}(t)}\right) \\
& =\left(k_{1 e} / \beta\right)^{2}\left(\gamma+\bar{P}_{n}^{-1}(t)\right)
\end{aligned}
$$

Thus the square of the initial rate is a linear function of $\bar{P}_{n}^{-1}$. In figure 9 we have plotted the squares of the initial rates at three different temperatures as a function of $\bar{P}_{n}^{-1}(t)$ and it is seen that data is quite compatible with eq (8). From the equation it follows that the ratios of the intercept to the slope yield value of $\gamma=3 \times 10^{-4}$ the ratio of the random initiation constant to the end initiation constant.

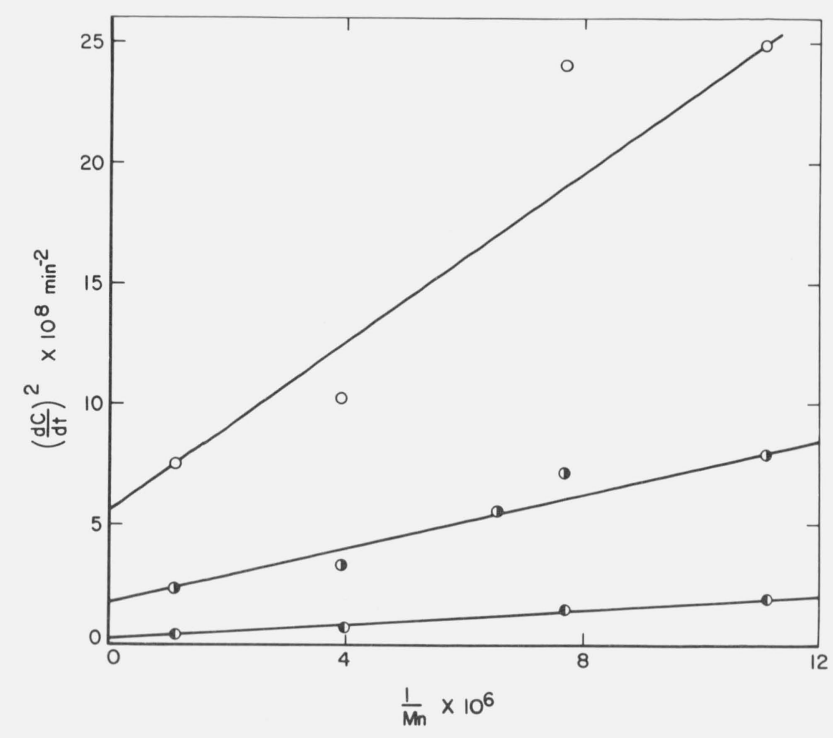

FIGURE 9. Thermolysis of thermal polystyrenes, variation of the square of initial rate with reciprocal number average molecular weight according to eq (8).

$$
\begin{array}{lll}
\mathrm{O}, 310{ }^{\circ} \mathrm{C} & , 300{ }^{\circ} \mathrm{C} & \text {. } 287{ }^{\circ} \mathrm{C}
\end{array}
$$




\subsection{Molecular Weight Relation}

The mechanism assumed leads to the following differential equation for the variation of polymer molecules with time.

$$
\begin{aligned}
\frac{d Q}{d t}=\frac{k_{3} R(t)\left[\bar{P}_{n}-1\right] Q(t)}{V(t)}+\frac{k_{4 c} R(t)^{2}}{V(t)} & \\
& -\left[k_{1 r} \bar{P}_{n}(t)-3\right] Q(t)-2 k_{1 e} Q(t) .
\end{aligned}
$$

Neglecting the quantities 1 and 3 in comparison with $\bar{P}_{n}(t)$, it follows from eq (5) that eq (9) reduces to:

$$
\frac{d Q}{d t}=\frac{k_{3} R(t) \bar{P}_{n}(t) Q(t)}{V(t)}-k_{1 e} Q(t) .
$$

Dividing eq (10) by eq (4) produces:

$$
\frac{d Q}{d C}=\frac{w_{0}}{m}\left[\frac{k_{3} \bar{P}_{n}(t) Q(t)}{k_{2} V(t)}-\frac{k_{1 e} Q(t)}{k_{2} R(t)}\right] .
$$

Upon inserting the relation for the steady state number of radicals obtainable from eq (6), eq (11) becomes:

$$
\begin{gathered}
\frac{d Q}{d C}=\frac{1}{(1-C)}\left\{\alpha \bar{P}_{n}(t) Q(t)-\frac{\beta \bar{P}_{n}^{1 / 2} Q(t)}{\left(1+\gamma \bar{P}_{n}\right)^{1 / 2}}\right\} \\
\alpha=\frac{k_{3}}{k_{2}} \frac{\rho}{m} \text { and } \beta=\left(\frac{k_{1 e} k_{4 c} \rho}{k_{2}^{2} m}\right)^{1 / 2}
\end{gathered}
$$

From the relation $Q(t)=\frac{w_{0}(1-C)}{m \bar{P}_{n}(t)}$ it follows that:

$$
\frac{d \bar{P}_{n}(t)}{d C}=-\frac{w_{0}}{m Q(t)}-\frac{\bar{P}_{n}(t)}{Q(t)} \frac{d Q(t)}{d C} .
$$

With the use of these two relations eq $(12)$ is connected to the following integrable expression:

$$
\frac{d \bar{P}_{n}(t)}{-\bar{P}_{n}(t)-\alpha \bar{P}_{n}^{2}(t)+\frac{\beta \bar{P}_{n}(t)^{3 / 2}}{\left[1+\gamma \bar{P}_{n}(t)\right]^{1 / 2}}}=\frac{d C}{(1-C)} .
$$

With the substitution $\chi=\left(\bar{P}_{n}^{-1}+\gamma\right)^{1 / 2}$ eq (13) is transformed to:

$$
\int_{C=0}^{C=C} d \ln (1-C)=\int_{\chi=\chi_{0}}^{\chi=\chi} \frac{-2 \chi_{2 d \chi}}{\chi^{3}-\beta_{\chi}^{2}+(\alpha-\gamma)_{\chi}+\beta \gamma} .
$$

The integral conversion as a function of $\bar{P}_{n}(t)$ is in the more frequent case:

$\ln (1-c)=A_{1} \ln \left|\left(\chi-r_{1}\right)\right|+A \ln \left[(\chi-a)^{2}+b^{2}\right]$

$$
-2 B \tan ^{-1} \frac{\chi-a}{b}
$$

$$
\begin{aligned}
-\left[A_{1} \ln \left|\left(\chi_{0}-r_{1}\right)\right|+A \ln \left(\chi_{0}-a\right)^{2}+b^{2}\right. & \\
& \left.-2 B \tan ^{-1} \frac{\chi_{0}-a}{b}\right]
\end{aligned}
$$

where $r_{1},(a+b i)$ and $(a-b i)$ are roots of the cubic expression in the denominator of the term on the right in eq (14), as found by Cardano's method, [28], and the coefficients are:

$$
\begin{aligned}
& A_{1}=\frac{-2 r_{1}^{2}}{r_{1}^{2}-2 a r_{1}+a^{2}+b^{2}} \\
& A=-1-\frac{A_{1}}{2} \\
& B=\frac{-A_{1} a-A a-A r_{1}}{b} .
\end{aligned}
$$

If the cubic expression has three real roots, they are found by the trigonometric method [29] and the solution is a sum of logarithmic terms only.

\subsection{Evaluation of Experimental Data}

With the use of eq (15) and the value of $3 \times 10^{-4}$ for $\gamma$, we can for given values of $\alpha$ and $\beta$ plot curves such

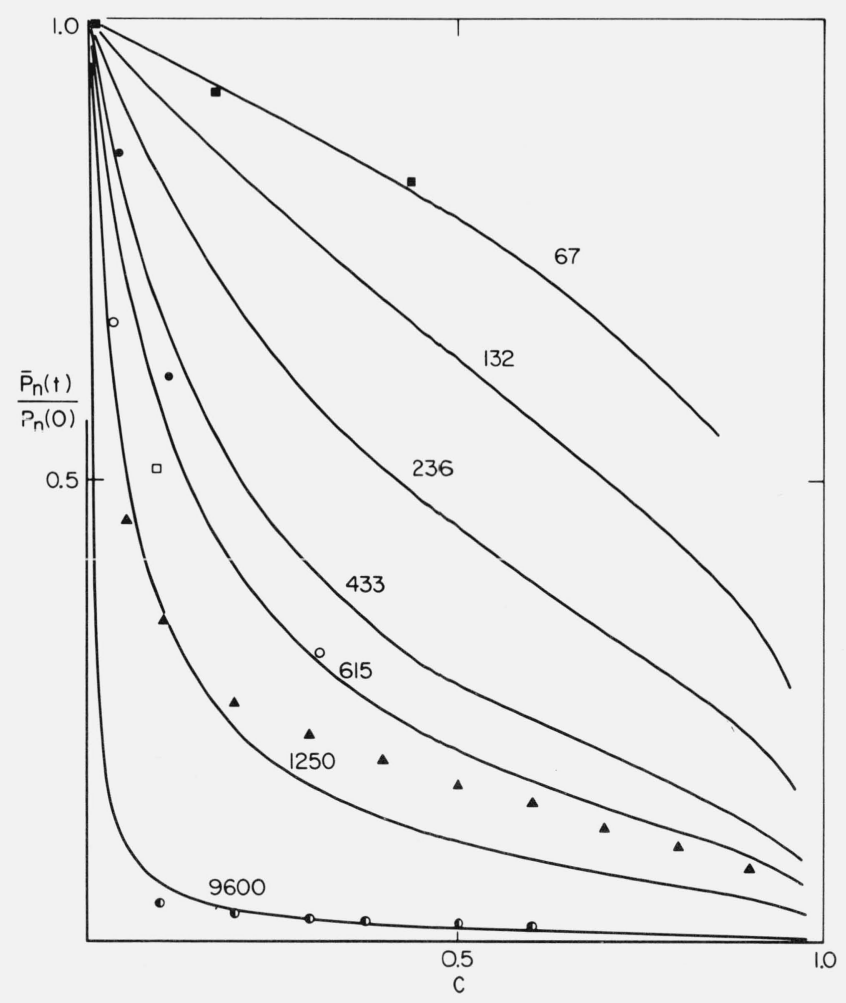

FIGURE 10. Thermolysis of thermal polystyrenes at $300^{\circ} \mathrm{C}$, variation of relative number average degree of polymerization with conversion.

Full lines are calculated from equation (15) with $\alpha=0.02, \beta=0.24$, and $\gamma=3 \times 10^{-4}$. The numbers above each line give the value of $\bar{P}_{n}(0)$ for the particular curve. The points are experimental for different polymers, initial $\bar{P}_{n}(0) ; \mathbf{0}, 67,236, \square, 433,0,615, \Delta, 1250$, and 0,9600 . 
TABLE 3. Degradation parameters for thermal polystyrenes

$$
\begin{aligned}
& \alpha=\frac{k_{3} \rho}{k_{2} m}=0.02 \\
& k_{1 r}=2.5 \times 10^{-7} \mathrm{~s}^{-1}\left(353^{\circ} \mathrm{C}\right) \\
& 8.7 \times 10^{-10} \mathrm{~s}^{-1}\left(300{ }^{\circ} \mathrm{C}\right) \\
& \beta=\left(\frac{k_{1 e} k_{4 c} \rho}{k_{2}^{2} m}\right)^{1 / 2}=0.24 \\
& k_{1 e}=8.5 \times 10^{-4} \mathrm{~s}^{-1}\left(353^{\circ} \mathrm{C}\right) \\
& 2.9 \times 10^{-6} \mathrm{~s}^{-1}\left(300{ }^{\circ} \mathrm{C}\right) \\
& \gamma=\frac{k_{1 r}}{k_{1 e}}=3 \times 10^{-4} \\
& k_{3} / k_{2}=2.1 \mathrm{~cm}^{3} / \mathrm{mol} \\
& k_{3} / k_{2}^{\prime}=5.25 \mathrm{~cm}^{3} / \mathrm{mol} \\
& Z=\left[\alpha+2 \beta\left(P_{n}^{-1}+\gamma\right)^{1 / 2}\right]^{-1} \\
& 0 \leqslant Z \leqslant 35.3 ; 0 \leqslant \bar{P}_{n} \leqslant \infty \\
& k_{3}^{\prime} / k_{2}=0.21
\end{aligned}
$$

$\sigma=\alpha\left[2 \beta\left(P_{n}^{-1}+\gamma\right)^{1 / 2}\right]^{-1} \quad 0 \leqslant \sigma \leqslant 2.4 ; 0 \leqslant \bar{P}_{n} \leqslant \infty$

as those shown in figure 10 . These plots give the variation in relative degree of polymerization, $\bar{P}_{n}(t) / \bar{P}_{n}(0)$, as a function of conversion. By trial a "best" choice of values for $\alpha$ and $\beta$ was made to give theoretical curves which "best" fitted the experimental points for the polymers with $\bar{P}_{n}(0)=67,1,250$, and 9,600 . With the exception of those for the 1,250 and the 9,600 sample the data points in figure 10 came from an earlier paper [13]. All points are for thermally prepared polystyrenes since it is evident from a comparison of figures 7 and 8 that anionic polystyrenes have a different mechanism of initiation at least in the early stages of the reaction. It is seen that the theory correlates nicely the observed experimental results for both a large range of conversion and a large range in degree of polymerization. Having a value for $\beta$ we can then with the use of the rate data determine the end initiation rate constant, $k_{1 e}$. Since we already know $\gamma$, we can also determine $k_{1 r}$. Values for these constants and other parameters are listed in table 3 .

Having established the relation between $\bar{P}_{n}(t)$ and $c$ we can with the aid of eq (7) and the numerical values for $k_{1 e}, \beta$, and $\gamma$ predict the rate for a given polymer as a function of conversion. Figure 11 shows such theoretical rate curves compared to experimental points. These points were taken from an earlier study [13]. With the present theory, the overall agreement is much improved over the previous theory [13].

For the smallest degree of polymerization sample, $\bar{P}_{n}(0)=67$, the agreement between theory and experiment is somewhat less than that for the other polymer samples. For this particular polymer however, the rate points were actually corrected by means of an Arrhenius plot from data taken at a much lower temperature. The observed discrepancy could easily be the result of an inaccurate extrapolation.

As a demonstration of the theoretical behavior of the logarithm of the initial rate as a function of the logorithm of the reciprocal molecular weight we calculate

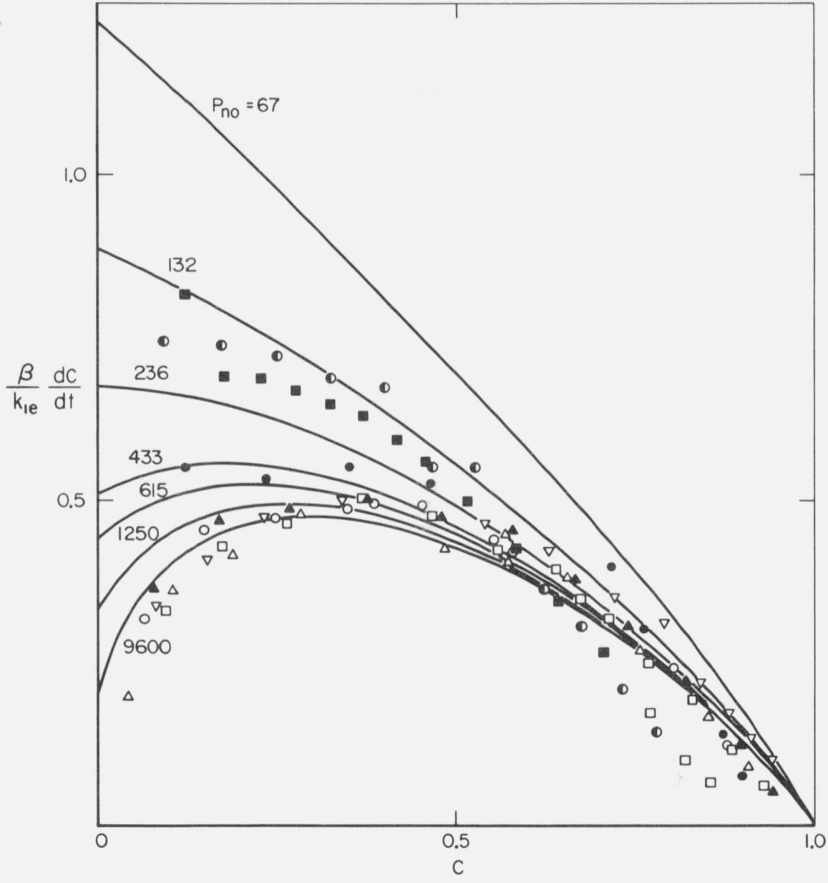

FIGURE 11. Thermolysis of thermal polystyrenes at $353^{\circ} \mathrm{C}$, variation of rate with conversion.

Full lines are calculated from eqs (7) with $\beta=0.24 ; \gamma=3 \times 10^{-4}$, values from eq (15). The numbers above each line give the value of $\bar{P}_{n}(0)$ for the particular curve. The points are experimental for different polymers. Initial $\bar{P}_{n}(0)$ ․ㅜㄹ, 67, $1,132, \bigcirc, 236, \square, 433,0,615$, $\Delta, 1250$, and $\nabla, 1462$.

the curves shown in figure 12. The experimental initial rates determined at $300^{\circ} \mathrm{C}$ are shown in the figure. The theoretical line is determined by means of eq (7) and the values of $\beta$ and $\gamma$ shown in table 3. The curve is shifted to give the best fit to the points by adjusting the values of the rate constant for end initiation, $k_{1}$. It is seen from the figure that at very high molecular weights the slope of the curve is zero. The reaction, 


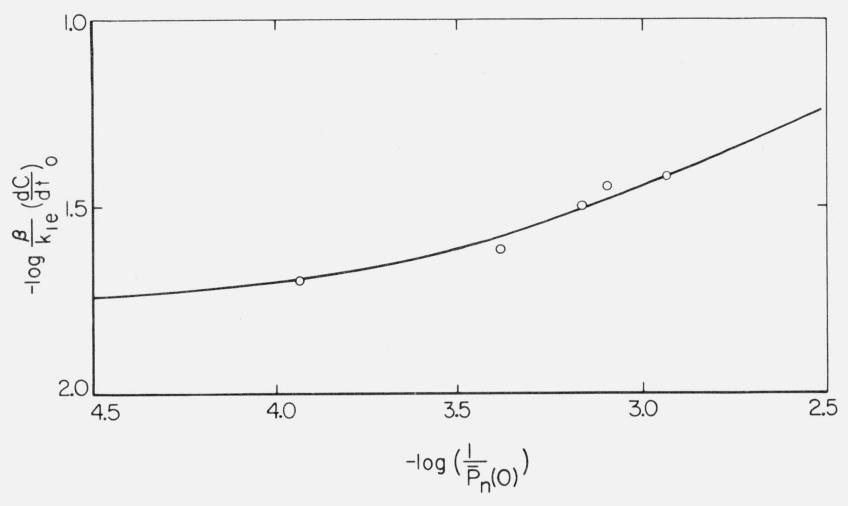

FIGURE 12. Thermolysis of thermal polystyrenes at $300^{\circ} \mathrm{C}$, variation of the logarithm of initial rate with logarithm of reciprocal $\overline{\mathrm{P}}_{\mathrm{n}}(0)$, comparison of theory and experiment.

being initiated by pure random scission, is independent of molecular weight. At very low molecular weights the initial rate becomes dependent on the square root of the $1 / M_{n}(0)$ or the number of ends. It is worthwhile noting that the experimental points fall in the transition region for the mechanism and that the slope of the tangent to the curve in this region is close to the value of 0.25 .

\subsection{Kinetic Chain and Zip Length}

Table 2 also presents the zip length, $Z$, defined as the average number of propagations per radical. In the theory herein described we have assumed that all weight loss is the result of propagation. Thus we have mathematically assumed:

$$
\frac{d^{\prime \prime} M "}{d t}=k_{2}^{\prime} \sum_{1}^{\infty} R_{i}+\bar{x} k_{3}^{\prime} \sum_{1}^{\infty} R_{i} \equiv k_{2} \sum_{1}^{\infty} R_{i}
$$

where $\bar{x}$ is the number average degree of polymerization for the nonmonomeric products. This means that the propagation constant, $k_{2}$, used in the theoretical relations above is a composite equal to $k_{2}^{\prime}+\bar{x} k_{3}^{\prime}$, where $k_{2}^{\prime}$ is the propagation constant for the production of pure monomer and $k_{3}^{\prime}$ is the constant for intramolecular transfer by which it is assumed that the majority of the other products are formed. From data $[10,30]$ in the literature on the yield of dimer, trimer, and other products we estimate that $\bar{x} \cong 3$.

In previous theoretical treatments [1,2] it was noted that intramolecular transfer was a means of producing nonmonomer in kinetic fashion equivalent to that for the production of monomer by propagation. The success of the present treatment lends weight to the conclusion that most nonmonomer is produced by intramolecular transfer. In this connection it is interesting to note that from this theoretical treatment we estimate for polystyrene degradation that $\approx 10.4$ intramolecular transfer acts occur per one intermolecular transfer. At a given temperature this value is a constant throughout the process. This information is deduced

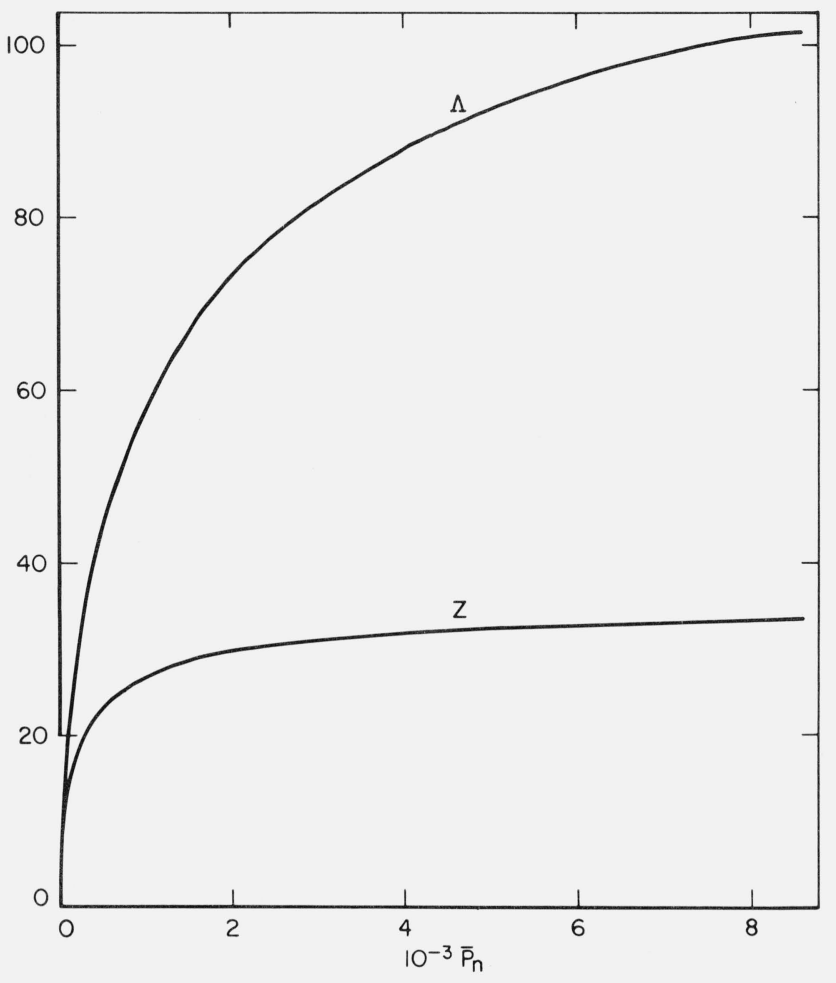

FIGURE 13. Thermolysis of thermal polystyrenes, variation of zip length, $(\mathrm{Z})$, and kinetic chain length, $\Lambda$, with number average degree of polymerization, $\mathrm{P}_{\mathrm{n}}$.

from the ratio $k_{3}^{\prime} / k_{3}$ shown in table 3 . The values of the other ratios involving $k_{2}, k_{2}^{\prime}, k_{3}$ and $k_{3}^{\prime}$ also shown in table 3 are estimated using the value of $\alpha, \bar{x}$ and the monomer yield, 40 percent. It is seen that the zip length, kinetic chain length, $\Lambda$, and the ratio of transfer to initiation, $\sigma$, a parameter used in previous treatments $[1,2,13,27]$, are all dependent on the degree of polymerization. In figure 13 a plot of $\Lambda$ and $Z$ as a function of $\bar{P}_{n}$ is presented. At very high $\bar{P}_{n}$ values, $\Lambda$ is about 100 and some photosensitization should be at least observable. However, the molecular weight if large decreases sharply in the initial stages of reaction and quickly drops to low values. The values shown are for the production of monomer and nonmonomer. The $\Lambda$ and $Z$ values for the production of pure monomer would be 0.4 times the values plotted. At $\bar{P}_{n}=200, Z=7$ for pure monomer. This compares with 3 to 5 used or deduced in previous work [13, 31]. Photosensitization studies with this polymer would therefore require careful work at low conversion using high molecular weight polymers.

In figure 14 the ratios $\Lambda / Z$ and $\sigma$ are shown as a function of $\bar{P}_{n}$. The difference between these two ratios is precisely unity, hence the two curves parallel each other. For pure random initiation all these parameters become constant, i.e., independent of $\bar{P}_{n}$. Therefore for the present system of mixed initiation they increase only slightly above $\bar{P}_{n}=8,000$. The use of termination by combination here as opposed to the previous [13] use of disproportionation results for 


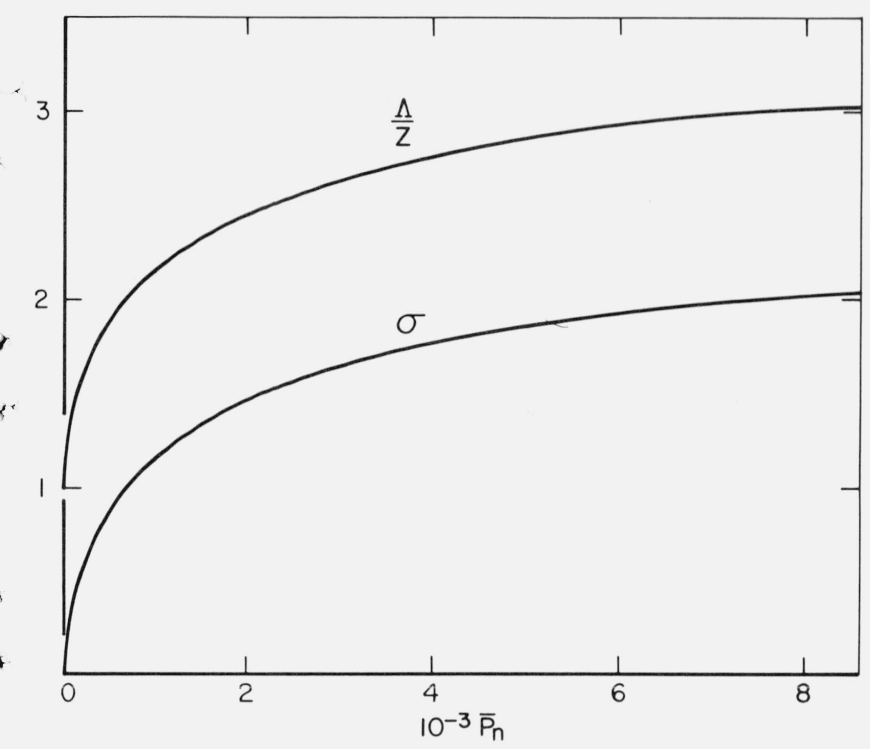

FIGURE 14. Thermolysis of thermal polystyrenes, variation of the ratio of kinetic chain length and zip length, $\Lambda / \mathrm{Z}$, and the transfer constant $\sigma$ [13] with number average degree of polymerization, $\overline{\mathrm{P}}_{\mathrm{n}}$.

$\bar{P}_{n}=615$ in a $\sigma=1$ instead of 0.045 . Also $\sigma$ previously decreased with $\bar{P}_{n}$ instead of increasing as shown in figure 14. Richards and Salter [16] from their study of the intermolecular transfer process using radiochemical techniques estimated $\sigma=1.2$, a value completely compatible with our present results.

Although all major aspects of the degradation phenomenon seen with thermal polystyrenes are accounted for by the present treatment it must be emphasized that this treatment neglects the direct molecular vaporization of small oligomers. This process is however insignificant until very high conversion when the $\bar{P}_{n}$ is very small. It should also be noted that the treatment does not specifically connect the initiation processes to the presence of specific structures in the polymer chain. The success of the treatment implies that either each molecule has certain probabilities for random and end initiation or that on the average there is a certain constant fraction of labile ends. Since the anionic polymers show no initial dependence on $\bar{P}_{n}$, the second possibility is indicated.

\subsection{Activation Energies}

Molecular weight as a function of conversion is nearly independent of temperature [13] and hence the parameters $\alpha, \beta$, and $\gamma$ have been taken to be independent of temperature in this treatment. However, without the very precise measurements over wider temperature ranges needed, we can make certain estimates from the available data.

The transfer ratio $\alpha$ should not vary greatly with temperature since the activation energies for abstraction $E_{3}$ and propagation $E_{2}$ usually have similar values.

Combining previous [13] and present data we estimate $0>E_{\beta}>-3 \mathrm{kcal}$ and $0<\boldsymbol{E}_{\gamma}<32 \mathrm{kcal}$ with log
$A_{r}<8.46$. Taking $E_{\beta}=0$ and the slopes in figure 9 where the data is taken at $300 \pm 10^{\circ} \mathrm{C}$, and $E_{1 e}=36$ and a $\log A_{1 e}=8.2$ are calculated. On the other hand rate data in figure 11 at $353{ }^{\circ} \mathrm{C}$ and previous data [13] yield the higher values $E_{1 e}=48 \mathrm{kcal}$ and $\log A_{1 e}=13.7$.

\subsection{Anionic Polystyrenes}

With the anionic polystyrenes the initiation process differs from that in the thermal polymers. From the curves in figure 7 it is clear that here initial rates are all essentially zero and independent of molecular weight. Yet the rate and molecular weight behavior of these polymers is nearly identical to that for the thermal polymer at conversions greater than 5 percent. It seems clear then that these polymers actually initiate at random in the limit of low conversion and more labile end initiating structures are produced as the conversion increases until a stationary concentration of end structures is attained.

With the anionic polystyrenes the key questions are what are the more labile initiating structures and how are they produced. It would seem on the basis of the mechanism deduced from the thermal polymers, that since the original ends are stable either intermolecular transfer or termination steps would be the source of the labile structures. From figure 6 it is seen, for instance, that for the polymer $\bar{M}_{n}=5,300$ the rate at first increases, and a maximum occurs at $\mathrm{C} \cong 0.2$. This is compatible with the build-up of the labile structures. Since the molecular weight for this polymer remains nearly constant with conversion (see fig. 5), one might conclude that the labile structure is that formed in the interior of the molecules by the recombination process. This would conflict with the fact that the virgin thermal polymer has labile structures. Thermal polymers have the most probable molecular weight distribution resulting from termination by transfer [32] either with monomer or thermal dimers. Since the molecular weights during pyrolysis for the low D.P. thermal polymers are nearly constant with conversion it is concluded then that labile structures are at ends produced by the intermolecular transfer process. Such labile end groups would be expected to have the unsaturated structure: $\sim \mathrm{CH}_{2}-\mathrm{C}=\mathrm{CH}_{2}$, assuming<smiles>C1=CC2=CCCCC2C=C1</smiles>

that $\alpha$ hydrogens are involved in the transfer process. However, $\beta$ hydrogen abstraction would lead to similar olefinic structures.

On the other hand conclusive evidence is not yet available that in a particular type polystyrene labile combination structures do not compete with labile end groups in the initiation process.

Another aspect to be expected initially with the anionic polymers is that random initiation produces the two types of radicals shown below:

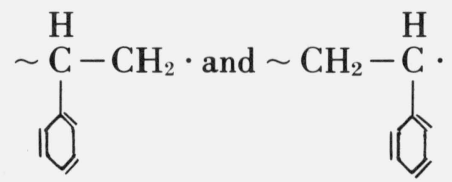


The primary radical is more active and would more readily transfer and disproportionate producing labile end groups and more quickly dropping the molecular weight.

\section{Conclusions}

The treatment developed for thermally prepared polystyrene satisfactorily explains a wide body of observations; rates, initial rates, molecular weight, changes in molecular weight distribution, and their dependence on conversion and initial molecular weight. The mechanism used is comprised of random and end initiation, depropagation, inter- and intramolecular transfer and most importantly termination by combination. The mathematical relations developed involved the number average molecular weight and the conversion. They are derived from differential relations for the total number of depropagating radicals, $R$, and the total number of molecules in the system, $Q$, and are therefore valid for any initial molecular weight distribution. A more complete treatment which would show the quantitative dependence of weight average molecular weight and molecular weight distribution on time or conversion would require both a computer, and considerable effort. This would be true even if the computer approach was adequately developed.

The experimental observations on the change in molecular weight distribution and in particular its convergence with conversion toward a distribution other than the "most probable" emphasizes the limited utility of previous kinetic treatments $[8,9]$ of degradation. Although these observations are not explicitly shown to result from the mechanism they are clearly the result of a coupling mechanism. Hence the use of the termination by combination step. This result and the variety of conceivable mechanisms is suggestive of the interesting possibility that specific narrow distributions including monodisperse ones may be produced by degradation.

Although the data for the anionic polystyrene is not correlated with theoretical relations, its degradation mechanism is clearly established to differ from thermal polystyrene chiefly in having initially pure randorn initiation which at higher conversion becomes supplemented and then overwhelmed by a component of end initiation.

\section{References}

[1] Simha, R., Wall, L. A., and Blatz, P. J., J. Poly. Sci. 5, 615 (1950).

[2] Simha, R., and Wall, L. A., J. Phys. Chem. 56, 707 (1952).

[3] Jellinek, H. H. G., J. Poly. Sci. 3, 850 (1948).

[4] Jellinek, H. H. G., J. Poly. Sci. 4, 1, 13 (1949).

[5] Grassie, N., and Melville, H. W., Discussions of the Faraday Society, The Labile Molecule, p. 378 (1947).

[6] Wall, L. A., J. Res. Nat. Bur. Stand. (U.S.), 41, 315-322 (1948) RP1928.

[7] Parker, M., Florin, R. E., and Wall, L. A., J. Res. Nat. Bur. Stand. (U.S.), 70A (Phys. and Chem.), No. 2, 115-131 (Mar-Apr. 1966).

[8] Gordon, M., Trans. Faraday Soc. 54, 1345 (1958).

[9] Boyd, R. H., J. Chem. Phys. 31, 321 (1959); Boyd, R. H., J. Poly. Sci. A-1, 5, 1373 (1967).

[10] Wall, L. A., Chapter V in Book, Pyrolysis, Ed., G. M. Kline, Part II, Analytical Chemistry of Polymers (Interscience, 1962).

[11] Jellinek, H. H. G., Encyclopedia of Polymer Science and Technology 4, 746 (1967).

[12] Cameron, G. G., and MacCallum, J. R., J. Macromolecular Sci., Macro. Rev. C1, 327 (1967).

[13] Wall, L. A., Straus, S., Flynn, J. H., McIntyre, D., and Simha, R., J. Phys. Chem. 70, 53 (1966).

[14] Richards, D. H., and Salter, D. H., Polymer 8, 127 (1967).

[15] Richards, D. H., and Salter, D. H., Polymer 8, 139 (1967).

[16] Richards, D. H., and Salter, D. H., Polymer 8, 153 (1967).

[17] Fetters, L. J., J. Poly. Sci. C, No. 26, 1 (1969).

[18] Fetters, L. J., J. Res. Nat. Bur. Stand. (U.S.), 70A (Phys. and Chem.) No. 5, 421-433 (Sept.-Oct. 1966).

[19] Feist, W. C., J. Poly. Sci. B3, 879 (1965).

[20] Bushuk, W. and Benoit, H., Can. J. Chem. 36, 1616 (1958).

[21] Wippler, C. and Scheibling, G., J. Chem. Phys. 51, 201 (1954).

[22] Altares, T., Wyman, D. P., and Allen, V. R., J. Poly. Sci. 2A, 4533 (1964).

[23] Alliet, D. F., Appl. Poly. Symp. 8, 39 (1969).

[24] Johnson, J. F., Porter, R. S., and Cantow, M. R., Rev. Macromol. Chem. 1, 413 (1969).

[25] Goetze, K. P., and Porter, R. S., J. Poly. Sci. Part C No. 35 189 (1971).

[26] Wall, L. A. Chapter 12 in Book, Fluoropolymers, Ed., L. A. Wall (Wiley-Interscience, N.Y., 1972).

[27] Simha, R., Wall, L. A., and Bram, J., J. Chem. Phys. 29, 894 (1958).

[28] Handbook of Mathematical Functions, Editors M. Abramowitz and I. A. Stegun, Nat. Bur. Stand. (U.S.), Appl. Math. Ser. 55 , 1054 pages (June 1964), see page 17.

[29] Burrington, C. B., Handbook of Mathematical Tables anả Formulas (Handbook Publishers, Inc., Sandusky, Ohio, 1946), pp. 7-9.

[30] Madorsky, S. L., Thermal Degradation of Organic Polymers (Interscience Publishers, N.Y., 1964).

[31] Simha, R., Transactions of the New York Acad. of Sci., 14, 151 (1952).

[32] Platt, A. E., Encyclopedia of Poly. Sci. and Tech. 13, 156 (1970).

(Paper 77Al-760) 